\title{
Teachers Reaction to a Tailored Incredible Years Classroom Management Programme for Children with ADHD Symptoms in Addis Ababa
}

\author{
Feruz Abdurahman Mohammed \\ Correspondence: Feruz Mohammed, School of Health Sciences, University of Canterbury, Private Bag 4800, \\ Christchurch, New Zealand. \\ Received: November 25, 2018 \\ Accepted: December 17, 2018 Online Published: February 26, 2019 \\ doi:10.11114/ijce.v2i1.4102 \\ URL: https://doi.org/10.11114/ijce.v2i1.4102
}

\begin{abstract}
Attention-Deficit/Hyperactivity Disorder (ADHD) is a persistent pattern of behaviours characterized by inattention, hyperactivity and impulsivity. Teaching children with ADHD is more stressful than teaching children without the disorder. This study examines teachers reaction towards a tailored Incredible Years Teacher Classroom Management programme aimed to enhance classroom management skills of a group of 10 teachers of children with ADHD symptoms in Addis Ababa, Ethiopia. This is the first study to evaluate the Incredible Years Teacher Classroom Management programme in African context. A one-group posttest-only experimental design was implemented. Ten teachers received the tailored Incredible Years Teacher training in a full-day session once a week for six weeks. The teachers drafted intervention plans at each session and implemented the strategies the following weeks in their classrooms. The teachers participated in an individual coaching sessions every week to help with implementation of the learned strategies and assess their level of performance. The teachers completed various structured and semi-structured questionnaires at the end of the intervention. The result of the study indicated that teachers were satisfied with the delivery of the programme; its content and practicality. Teachers reported that they were happy with the effects of the programme on children's behaviour in the classroom. The teachers also indicated that they would recommend the programme to other colleagues. In light of the findings, teachers' reaction, limitations and implications for future research were discussed.
\end{abstract}

Keywords: Incredible Years teacher programme, teacher professional development, ADHD intervention, tailoring teacher training

\section{Introduction}

Attention-Deficit/ Hyperactivity Disorder (ADHD) is one of the most prevalent neurodevelopmental disorders in childhood (Zhou et al., 2015). According to the Diagnostic and Statistical Manual of Mental Disorders-Fifth Edition (DSM-5), ADHD is defined as a persistent pattern of behaviours characterized by inattention, hyperactivity and impulsivity (American Psychiatric Association [APA], 2013). These core symptoms begin in early childhood and several of these symptoms appear before the child turns 12 years (APA, 2013) and symptoms persist up to adulthood (APA, 2013; Barkley, 2006; Barkley, 2015).

With a reported prevalence rate of $11 \%$ among school age children in the United States based on parent-reported indicators, ADHD is believed to be the most encountered child behaviour disorders by primary health care providers (Visser et al., 2014). A systematic review by Bakare (2012) showed a prevalence rate of ADHD between 5.4\% and 8.7\% among school children in sub-Saharan Africa, including Ethiopia. In Ethiopia, there is no diagnostic centre for ADHD nor do intervention guidelines exist at a national level. However, recently, Messaria (2013) studied the prevalence, correlates, and comorbidities of ADHD in the capital city, Addis Ababa, involving a sample of 1543 primary school children. The children were assessed based on the DSM-IV-TR (APA, 2000) criteria. The study reported a prevalence rate of $8.55 \%$ which suggests the need for evidence-based intervention in primary schools in Addis Ababa.

It is well documented that ADHD significantly affects the behaviour and academic functioning of children with the disorder (Bawerja, Mattison, \& Waxmonsky, 2015; Clarke et al., 2015; Corkum, McGonnell, \& Schachar, 2010; Shaughnessy \& Waggoner, 2015). It has been estimated that $85 \%$ of children with ADHD show poor academic performance because of core behaviour symptoms and executive functioning problems involved (Barkley, 2006). Such children struggle with inhibiting or delaying responses which are evident in a variety of classroom disruptive behaviours such as leaving seats, calling out, or interrupting the teacher. These children display a wide range of school 
deficits such as lower on-task behaviour (Dekker et al., 2017; Imeraj et al., 2013), incomplete homework and poor academic performance across subjects (Jitendra et al., 2008), distractibility, disorganization, confusion over direction and poor handwriting (Flick, 2010). It has been reported that children with ADHD are approximately 2.5 times more likely to engage in off-task behaviours compared to peers without the disorder (Vile Junod, DuPaul, Jitendra, Volpe, \& Cleary, 2006). Because of such high rates of off-task behaviour in the classroom and inconsistent work productivity, children with ADHD score lower in standard achievement tests and struggle with academic success (Arnold, Hodgkins, Kahle, Madhoo, \& Kewley, 2015).

So significant is the impact of ADHD on the behaviour and school functioning in children with the disorder that planning effective and appropriate school-based interventions is imperative. Because of these practical school problems, there has been a great interest in the development, implementation and evaluation of teacher-mediated interventions for children with ADHD (DuPaul, Eckert, \& Vilardo, 2012).

The importance of teacher involvement in the application of evidence-based school intervention for children with ADHD has been studied, but teacher related factors such as teacher attitude, knowledge, understanding and experience with these children are also believed to affect the success of treatment delivered at school. Flick (2010) mentioned that teacher's knowledge of ADHD is one of the most significant factors in building effective teacher-student interactions. Despite the fact that teachers' knowledge of ADHD is important, studies reported the existence of teachers' unfavourable attitudes towards the children and poor knowledge of the disorder (Perold, Louw, \& Kleynhans, 2010); and these researchers noted how teachers with that even little knowledge of the disorder can effect quite a big (relative) change in the children's learning and behaviour.

It is clear a teacher's inadequate knowledge about ADHD and lack of skills to accommodate such children in the classroom puts the teacher under stress. Studies have shown that teaching children with ADHD is more stressful than teaching children without the disorder (Ellis, 2013). In particular, teachers with limited knowledge about the disorder and those who do not use specific teaching techniques to help the children in the classroom experienced high levels of stress in teaching the children. This suggests that teachers of children with ADHD need to develop specific skills to manage the behaviour of the children in the classroom.

Considered together, these reviews and studies strongly recommend teacher training and professional development to enhance teacher's knowledge and understanding of ADHD. In particular, primary school teachers need to get accurate information about ADHD and practice specific teaching techniques to help children in the classroom, as most of the studies of children with ADHD were conducted in primary schools. For this to occur there is a need for the provision of professional development addressing the specific characteristics of the disorder and the educational needs of individual child with ADHD (Barkley, 2006).

\subsection{Incredible Years Teacher Classroom Management Programme (IYTCM)}

Incredible Years Teacher Classroom Management programme (IYTCM) (Webster-Stratton, 2008) is one of the most researched evidence-based classroom management approaches built on the principles of positive and proactive behaviour management, which is a contemporary approach to manage classroom behaviours. The IYTCM programme promises to strengthen teacher-child relationships and develop children's problem-solving and social skills.

One of the appealing features of the Incredible Years (IY) programme is the possibility of the programme to be tailored for different groups of children with various behaviour or developmental issues; teacher or family conditions; and various cultural and economic contexts (McIntyre, 2008; Webster-Stratton \& Reid, 2010). Based on ADHD theoretical assumptions, three basic issues are important to incorporate in the intervention of these children a: (a) provision of continuous intervention in a natural setting where the desired behaviour is to occur (Barkley, 2006); (b) the importance of teacher-mediated intervention, as teachers play a tremendous role in the child's behaviour, academic, and social development (DuPaul et al., 2012); and (c) the application of reinforcement contingencies for children with ADHD (Luman, Oosterlaan, \& Sergeant, 2005). IYTCM has promised to address these issues. Teachers in the IYTCM programme are expected to integrate the strategies with the daily lesson plans and implement continuously monitoring the changes on individual child. Systematic application of reinforcement contingencies (e.g., positive attention, praise, and consequences for breaking rules) is the most important principle of the IYTCM intervention.

Webster-Stratton, Reid, and Stoolmiller (2008) evaluated the effects of IYTCM and Incredible Years child programme in preventing conduct problems and improving school readiness. The study involved 153 teachers and 1768 children from 120 classrooms. Children from moderate to high risk groups - poverty-related risk factors, were selected. The teacher outcome measures involved multilevel procedures including repeated measures, pre- and post-measures, within teacher analysis, within classroom analysis and across classroom measures as some of the classrooms had multiple teachers. The teachers received four days training (28 hours) on IYTCM which was offered on a monthly basis. The authors reported that teachers in the intervention group had shown significant improvement in classroom management 
style during the post-treatment assessment compared to the pre-treatment. Teachers in the intervention group reported greater involvement from parents of their students than the parents in the control group. The result of teachers' programme satisfaction suggested that teachers were satisfied with the programme. The teachers rated the workshop techniques including trainer's leadership skills, group discussion, video examples and role plays as very helpful on a 4-point scale (Webster-Stratton et al., 2008).

The effectiveness of the IYTCM programme has also been established for teachers of preschool children. Carlson, Tiret, Bender, and Benson (2011) studied the effects of IYTCM in preschool teacher's classroom management strategies. The study aimed to increase the frequency of use of positive classroom management strategies, such as giving attention to appropriate behaviour, increasing home-school communication, and decreasing the use of negative classroom management strategies (e.g. commenting on the child's inappropriate behaviour, etc.). The study selected 24 female teachers of children ( 3 to 5 years old) to participate in the IYTCM training. The teachers received the training once a week in eight sessions over a 2 to 3 month period, with the aim of integrating the programme with the teachers' weekly schedules. The teachers' use of classroom strategies, and communication and collaboration with parents was measured. The results indicated that teachers significantly increased the use of positive classroom management strategies during follow-up and post training assessment compared to the baseline (Carlson et al., 2011). Similarly, the frequency of teacher parent interaction increased during the post training and follow-up assessment compared to the baseline. The frequency of perceived use of inappropriate strategy, such as commenting on child's inappropriate behaviour, in the classroom also decreased during the follow-up compared to the baseline or post training measures; however, the study did not measure the impact of the training on children's behaviour.

Hutchings et al. (2007) were the first to conduct an independent evaluation of the IYTCM outside the USA. The authors reported on the response of teachers to the IYTCM programme in North West Wales, in the UK. The programme involved training of 23 teachers, which was delivered in both Welsh and English on a full day session per month over five months. About $65 \%$ of the teachers attended all the sessions. The study examined the acceptability of the programme first and subsequently observed the teacher-student interactions. Teachers programme satisfaction was measured in terms of usefulness of the programme, confidence in using the principles, putting the programme into practice, and the strategies to improve home-school communications. Each item was measured on a 5-point scale with maximum score of 5. Teachers were also interviewed on areas of personal information about the course, application in the classroom and general comments and recommendations. The results indicated overall teacher satisfaction with the programme. The practicality of the programme received the highest score compared to confidence in using the strategies and usefulness of the programme. Strategies to work with parents were rated the least useful, suggesting that the strategies included in the training were not considered feasible by all teachers. The majority of teachers $(91 \%)$ reported that they would recommend the training to other teachers (Hutchings et al., 2007).

Davenport and Tansey (2009) also studied the effectiveness of the IYTCM programme for primary teachers from multiple schools in the East Coast of Ireland, UK. Fifteen teachers participated in the training offered over a five month period. The teachers completed an open-ended qualitative evaluation of the IYTCM programme. Analysis of the findings revealed that the teachers reported a significant improvement in their teaching efficacy particularly in classroom management and this result was maintained at the 1-year follow-up (Davenport \& Tansey, 2009). All participating teachers in the study reported that they were 'confident' or 'very confident' at managing both current and future behaviour problems. The teachers also reported that they would recommend the workshop to colleagues.

Recently, Hutchings, Martin-Forbes, Daley, and Williams (2013) investigated the effects of IYTCM in teachers' behaviour in addition to examining the effect of the programme on children's behaviour. The researchers tested the following two hypotheses: (a) teachers would display more positive and less negative behaviours in the classroom after the intervention; (b) teachers would show more positive behaviours to children with behaviour concerns after the intervention. Sixteen female primary school teachers of 3-7 years old children were selected from 11 primary schools. A total of 80 children who had low scores on the SDQ and 27 children who scored higher on the measure were selected. The teachers received the training in a full-day session once a month for five months. Teachers were asked to practice the strategies between sessions; however, they did not receive ongoing coaching between sessions. Both child and teacher behaviour were assessed pre- and post-intervention and teacher-student interactions were also observed.

The results showed that teachers' negative behaviour decreased for the intervention group at post-test compared to the control group. Based on the findings, the researchers recommended the use of IYTCM to primary school teachers and they suggested the policy makers in the UK to consider the programme (Hutchings et al., 2013).

The effectiveness of IYTCM has been established for groups of teachers mainly in the western part of the world and in some developing countries (Baker-Henningham, Walker, Powell, \& Gardner, 2009); however, it has not been tried in African countries and this is the first study conducted in Ethiopia. It was very important to try out the IYTCM in the 
Ethiopian context, as teachers in Ethiopia also struggle to manage children with ADHD symptoms, although the education and schooling system is different, so is the culture. The present study intends to tailor IYTCM for teachers of children with ADHD symptoms (IYTCM-ADHD) in Ethiopia and examines the teachers' reaction to the programme.

Ethiopia is one of the fastest growing economies in Africa (Gray, 2018), with multilingual and multicultural nation. The country is facing multifaceted educational challenges from primary through to tertiary level. Instruction in government schools mainly focuses on traditional ways of teaching, that is, teacher-centered approach in which teachers talk and children are required to listen. The curriculum gives less emphasis to abstract thinking and problem solving skills, and more emphasis to fact-based content (Kocsev, Hansen, Hollow, \& Pischetola, 2009). According to a study conducted on the quality of teaching and learning in primary schools in Ethiopia, the assessment of curricular materials revealed that the teaching materials were not presented in a way that encourages independent and self-reflective way of learning (Serbessa, 2006). Regarding teacher's professional development training, primary school teachers in Ethiopia have little chance of participating in professional development trainings particularly on classroom management skills. Thus, children with ADHD in the Ethiopian context do not receive specific school based intervention, as teachers are not specifically trained to support these children in the classroom.

A study by Serbessa (2006) revealed that $87 \%$ of participating teachers reported that they had never received professional development training since they started teaching. Because of a lack of teacher knowledge of alternative discipline strategies, the use of harsh punishment, including corporal punishment, is widespread in schools. Although corporal punishment is prohibited in the Ethiopian constitution, it is common practice in schools.

\section{Research Method}

A one-group posttest only experimental design was used for this study. This design was chosen because of its practicality and convenience to measure if the teachers benefited from the training. This design also helped to complete the study within the time frame before the school year ended. All participating teachers joined the study by interest and full dedication and informed consent was obtained before the training. The teachers were given training for 6 weeks on the tailored IYTCM-ADHD. The teachers drafted intervention plans for the target children at each session and implemented the strategies in the classroom the following weeks. The teachers participated in an individual coaching sessions every week to help with implementation and assess their level of performance. In addition, teachers' reaction to the programme was assessed using a number of structured and semi-structured questionnaires at the end of the intervention.

\subsection{Setting}

The study was conducted in one of the community-based primary schools in Nifas-Silk Lafto sub-city of Addis Ababa City Administration. The primary school serves children from grade 1 through 4 and had eight sections, two sections at each grade level. The number of children per classroom ranged from 24 to 36 . Children were taught seven to eight subjects every day by different teachers, with the school day divided into eight periods of 45 minutes each. Each section had a homeroom teacher who served the section throughout the academic year. The homeroom teacher has pastoral responsibilities for students in addition to teaching, which includes attending the flag ceremony with the children every morning before classes start, checking absentees, preparation of grade reports for each child, and facilitating communication between the school and home.

\subsection{Participants}

After the school's informed consent had been obtained to participate in the study, information and invitation sheets were circulated to selected teachers of the primary school to come to meet the researcher. A total of 12 teachers who had either a degree or a diploma in teaching and those who could read and understand English attended the first meeting to discuss the study. Teachers were given a brief description of the intervention and the teacher training. After an hour discussion, 10 teachers signed the consent form to participate except two teachers who could not participate for various reasons.

Demographic characteristics of participating teachers are shown in Table 1. As shown in the table, there were 10 teachers, 6 men and 4 women with an average of 7.7 years of teaching experience. None of these teachers had received specific training on classroom management skills since they started teaching. Two teachers had received continuous professional development in teaching English, and one teacher had received training on Student Performance Assessment and Report. Of 243 children enrolled, a total of nine children with ADHD symptoms were identified as target children based on teacher nomination and teacher and parent reports of child behaviour. In addition, nine comparison children without ADHD symptoms, who were matched for age and gender, were included. Of the 10 teachers, seven were either homeroom teachers or main subject teachers who meet the children on daily basis. The other three were team teachers who taught participating children twice a week. 
Table 1. Demographic Characteristics of Participating Teachers

\begin{tabular}{|c|c|c|c|c|c|}
\hline Teacher & Gender & $\begin{array}{l}\text { Years of } \\
\text { Teaching } \\
\text { Experience }\end{array}$ & $\begin{array}{l}\text { Teaching } \\
\text { Subject }\end{array}$ & $\begin{array}{l}\text { Professional } \\
\text { Development } \\
\text { Training } \\
\text { Previously } \\
\text { Received }\end{array}$ & $\begin{array}{l}\text { Grade Levels } \\
\text { Taught }\end{array}$ \\
\hline $\mathrm{T} 1 *$ & $\mathrm{~F}$ & 5 & Science in Amharic & No & Grade 2 and 4 \\
\hline $\mathrm{T} 2 *$ & $\mathrm{~F}$ & 2 & Amharic & No & Grade 3 and 4 \\
\hline T3 & M & 8 & Science in English & No & Grade $1,2,3$ and 4 \\
\hline $\mathrm{T} 4$ & $\mathrm{~F}$ & 3 & IT (Computer) & No & Grade $1,2,3$ and 4 \\
\hline T5 & M & 2 & Physical Education & No & Grade $1,2,3$, and 4 \\
\hline T6 & $\mathrm{M}$ & 4 & Mathematics in Amharic & No & Grade 2, 3 and 4 \\
\hline $\mathrm{T} 7$ & $\mathrm{~F}$ & 5 & English & CPD & Grade 1 and 2 \\
\hline T8* & $\mathrm{M}$ & 13 & English & CPD & Grade 3 and 4 \\
\hline T9 & M & 25 & Unit Leader (Mathematics) & No & Grade $1,2,3$ and 4 \\
\hline $\mathrm{T} 10 *$ & M & 10 & Mathematics in English & SPA & Grade $1,2,3$ and 4 \\
\hline
\end{tabular}

\subsection{Teacher Training/Intervention}

The intervention involved training of teachers using the IYTCM programme. The existing programme was tailored for children with ADHD (IYTCM-ADHD) in Addis Ababa, Ethiopia. Maximum effort was made to tailor the prescribed programme to suit the specific needs of children with ADHD, including the content of the training sessions, assignments, handouts, and readings. Participating teachers received 36 hours of training over 6 weeks using the tailored IYTCM-ADHD. The teachers drafted behaviour plans for each target child focusing on problem behaviours identified. Then, the teachers were expected to implement their intervention plans in the classroom with the identified children with ADHD symptoms, which they prepared during training sessions.

\subsection{Tailoring IYTCM}

The IYTCM was tailored into IYTCM-ADHD in this study in order to suit teachers of children with ADHD symptoms. The training material was tailored based on evidence-based studies of children with ADHD and in ways that were acceptable and practical in the Ethiopian context. A range of IYTCM series standard materials were used without any changes; however, some changes were made to the existing programme content, handouts, and the reading materials. Minor changes were made to the assignments and the coaching sessions. The tailoring of IYTCM also involved adding ADHD related concepts and information, replacing some of the existing strategies with evidence-based strategies for children with ADHD, and providing supporting evidences to the standard IYTCM principles in relation to ADHD. The following were some of the major changes made to suite teachers and school children with ADHD in Addis Ababa, Ethiopia:

\# Readings on the definition of ADHD, the nature and course of the disorder were provided.

\# Modifications of instruction and identification of triggers for off-tasks behaviour (Carroll et al., 2006) were included.

- Peer-mediated conflict resolution and computer assisted instructions for children with ADHD were added (as the study school used computers for instruction).

* Collaborative Strategic Reading approach for teachers by Vaughn and Klingner (1999) was taught to replace Dialogic Reading strategy for parents.

* The model for managing antisocial and off-task behaviour from Walker, Colvin, and Ramsey (1995) was taught to replace the strategies for ignoring, redirecting and time-out.

* Self-monitoring countoons for children with ADHD- cartoon versions that help children to monitor and record their behaviour (Daly \& Ranalli, 2003) was used for target behaviours.

* Games such as 'connect-the-dots' was used for teachers to play with target children.

* Information sheets on 'Sleep for Children' ("Nationl Sleep Foundation”, n.d.) were translated into Amharic (Ethiopian official language) and disseminated for teachers and parents to identify causes of attention problems. Sleep problem is common in children with ADHD and is associated with child poverty, family outcomes and the caregiver's mental health (Sung, Hiscock, Sciberras, \& Efron, 2008).

* Volcano Scale-My School Triggers (Do2learn, 2010) was adopted and used to help teachers train 'calm down' strategies for target children. 
\# Examples of possible prizes that Ethiopian children would enjoy were listed and translated into Amharic for better understanding and application.

* Topics on child rights and child positive disciplining strategies in relation to children with ADHD were added, as Ethiopia has high rate of corporal punishment in schools (Portela \& Pells, 2015).

\subsection{Training Procedure}

The teacher training procedures were followed on six successive Saturdays. The training was conducted during the second semester of the academic year, according to the Ethiopian school system (between February and April). The teacher training methods included group discussion; video modelling; role-plays and rehearsal. Teachers were also given assignments to practicing key strategies; developing individual behaviour plans; and participating in coaching sessions (15 to 20 minutes). During the workshops, the standard IYTCM procedure was followed. At each workshop, teachers were introduced about the session's objectives, the topics to be discussed, and the activities to be followed. Teachers brainstormed about concepts, watched pre-selected vignettes and role-played in a pair - one teacher being a student with ADHD symptoms and the other being a teacher. Teachers drafted behaviour plans for each target child focusing on problem behaviour. Teachers completed the self-reflection inventory for each session and set up goals. The assignment for the mid-week coaching would be reviewed. At the conclusion, teachers evaluated sessions.

In terms of teacher programme implementation procedures, intervention plans for target children were drafted every workshop session following the standard IYTCM manual. The plans focused on problem behaviours in the children. During the week following each session, the individual child plan was implemented, with supportive individual teacher coaching. The plan was updated and revised at the next workshop, incorporating new information as discussed. The team teachers neither planned for participating children with ADHD nor participated in the coaching sessions as they did not have contact with the children on a daily bases. They did, however, discuss the plans prepared by the homeroom or main subject teachers during the workshops. The team teachers were also expected to implement the plans as discussed with planning teachers when they meet target children.

\subsection{Programme Fidelity}

Maximum effort was made to attain fidelity of the programme. Participating teachers joined the programme with full interest, without any conditions, so that there was high degree of intervention integrity. The following strategies were used to attain fidelity of the programme implemented for teachers of children with ADHD in the Ethiopian context. The group leader (the researcher) was trained in the IYTCM group leadership for about 19 hours by one of the IY accredited peer coaches in New Zealand before delivering the training. The standard programme dosage, order, and protocol were maintained and the check lists were completed. Some of the contents of the standard manual were adapted for children with ADHD in the Ethiopian context. The training procedure prescribed in the manual was followed throughout the programme and some of the training materials such as handouts, blackboard notes, worksheets, self-monitoring sheets, and sample letters for parents and the thought bubble diagrams were translated into Amharic (Ethiopian official language) for better understanding and practice. Detailed programme contents and session protocols were specified before the training including the videos to be shown, the questions to be asked, the role plays and the weekly assignments. Each teacher was given a copy of the book, How to Promote Children's Social and Emotional Competence (Webster-Stratton, 1999). The teacher workshop checklists were completed for each session. Teachers received praise, reinforcement and gift items as incentives upon participation and accomplishment. Teachers were involved in behaviour intervention planning and reviewing process for the target children. Teachers were also provided with stationary items such as stickers, pencils, highlighters and notebooks to help with implementation of some of the strategies with the children in the classroom. In addition, each teacher participated in the mid-week coaching session for 15 to 20 minutes. This meeting helped to evaluate individual teacher's successful application of the learned strategies and the strategies with which teachers reported difficulty. Teachers involved in behaviour intervention planning and reviewing process. In addition, all teachers received on-going supervision to help with implementation and set up new goals.

\subsection{Measures}

\subsection{Teacher Attendance}

Teacher attendance and participation in the workshop were recorded as an indicator of teacher interest and satisfaction in the programme. Teacher presence at the workshops; participation and involvement in developing behaviour plans; and availability for mid-week teacher-coach meeting were considered as important aspects of teacher attendance. Teachers signed the attendance sheet provided at the end of each session. Teacher participation in developing behaviour plans and presenting the plan to the group was recorded in the workshop monitoring checklist each week. In addition, the teacher-coach meeting held in mid-week was recorded for each teacher. The total number of workshop attendance was counted for each teacher and converted into a percentage. 


\subsubsection{Workshop Session Evaluation Form (Webster-Stratton, 2008)}

The IY teacher programme session evaluation form (Webster-Stratton, 2008) was adapted for this study to evaluate the workshops. Teachers evaluated each workshop session on the usefulness of the content, video examples, the leader's teaching and quality of the group discussion. Four themes on a 4-point scale ranging from (0) not helpful to (3) very helpful were included. The scores for each session were added and converted into a percentage. The average percentage was calculated to describe the overall workshop session evaluation. The purpose of session evaluation was to assess teachers' feedback on each workshop and arrange individual time for those teachers who needed further discussion or clarification on the learned concept or skill. Teachers' evaluation of the workshop on the scaled questionnaire was counted for each teacher across the six sessions and converted into a percentage, such that higher scores represent a more positive attitude.

The teachers also evaluated the workshop techniques used on a 6-point rating scale. The questions included about the benefits of reading the IY book and other reading materials provided; the importance of behaviour plan preparation during the workshops; rehearsal of the learned skills in the workshops; and the reading and skill practice assignments for the week. The teachers were also asked if the support received from other trained colleagues were important to implement intervention strategies in the classroom.

\subsubsection{Coaching Session Report (Webster-Stratton, 2008)}

The IY teacher coaching summary report form (Webster-Stratton, 2008) was adapted for this study. The purpose of teacher-coach meeting was to evaluate individual teacher's successful application of the learned strategies and the strategies with which teachers reported difficulty. A teacher-coach meeting was conducted with individual teachers each week for about 15 to 20 minutes during the training period. Discussion during this meeting focused on major strategies of the workshops expected to affect target children's behaviour performance; and those assignments and homework expected to be completed during the week. In addition, anecdotal records of the teacher's accomplishment were collected during each meeting. Teachers also discussed the self-reflection evaluation reports where teachers indicated their position in terms of the implementation of the learned strategies. The coaching report is summarized for individual teacher indicating the strategies the teachers implemented successfully and those strategies the teacher needed more time. The teachers report was evaluated against the number of strategies expected at each coaching session.

\subsubsection{Teacher Workshop Satisfaction Questionnaire (Webster-Stratton, 2008)}

The IY teacher workshop satisfaction questionnaire (Webster-Stratton, 2008) was adapted to measure teacher's satisfaction on the tailored IYTCM-ADHD programme. The questionnaire has four thematic areas: the effectiveness of specific behaviour strategies used to help target children; confidence in managing future behaviours in the classroom; recommending the programme to other teachers/colleagues and overall programme evaluation. The questionnaire consists of 32 items on a 7-point scale and 5 semi-structured open ended questions on the overall programme evaluation. Teacher satisfaction on the overall programme was reported by computing the overall scores obtained on the subscales (ranging from 0 to 48) and converted into a percentage, such that higher scores represented a more positive attitude.

\section{Results}

Ten teachers from Grade 1 through 4 participated in the IYTCM-ADHD programme. Six training sessions (workshops) were held on consecutive Saturdays and all participating teachers attended 100\%. All the ten teachers participated 100\% in all the six individual teacher-coach meetings held in the mid-week.

All participating teachers evaluated the workshop content, videotape examples, leader's teaching and the group discussion as either 'helpful' or 'very helpful' in all the six workshops (as shown in Table 2). The teachers rated the leader's teaching technique as the most helpful as $87 \%$ and the group discussion as $45 \%$.

Table 2. Teacher Evaluation of Workshop Sessions

\begin{tabular}{lll}
\hline Subject & Helpful (\%) & Very helpful (\%) \\
\hline Content & $20 \%$ & $80 \%$ \\
Videotape & $43 \%$ & $55 \%$ \\
Leader's Teaching & $13 \%$ & $87 \%$ \\
Group Discussion & $55 \%$ & $45 \%$ \\
\hline
\end{tabular}

Note. one missing data point on video tape evaluation

Teachers evaluated the workshop techniques on a 6-point rating scale (Figure 1). The teachers rated the IY book and reading materials provided as extremely useful as $95 \%$. Teachers rated the importance of behaviour plan preparation 
during the workshops as $82 \%$ and rehearsal of the learned skills in the workshops as $78 \%$. Support gained from other teachers was rated the least useful as $72 \%$.

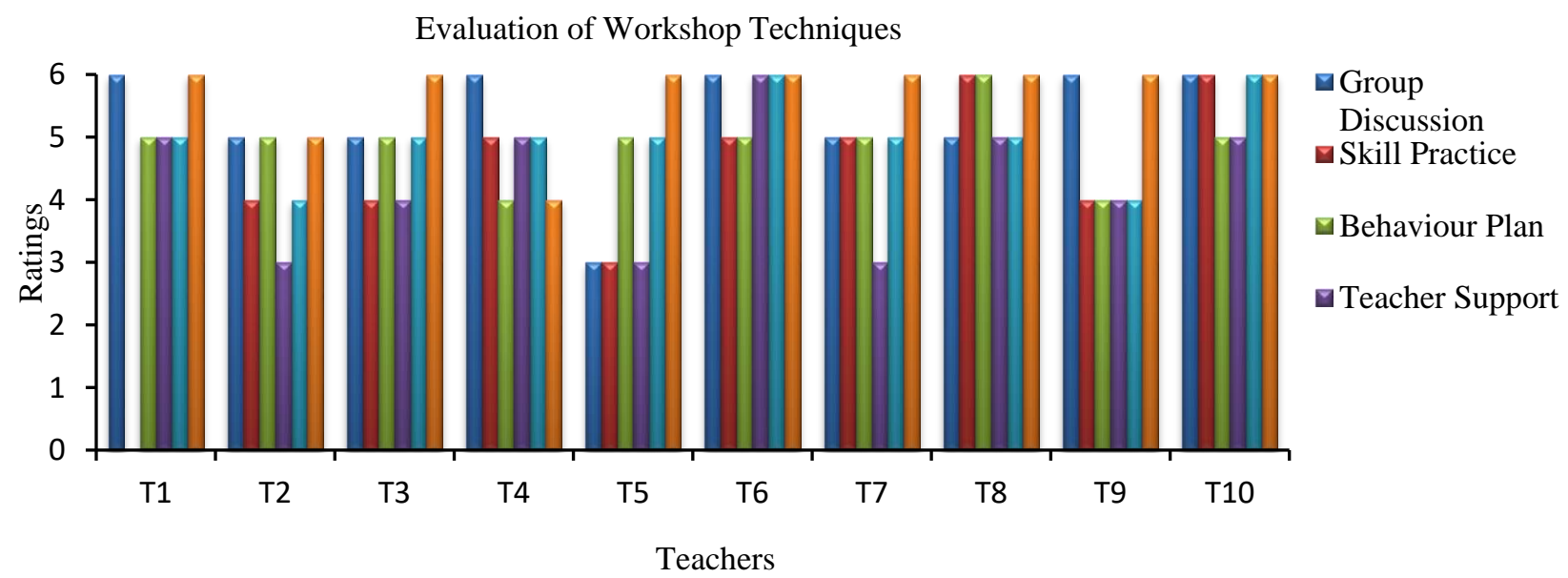

Figure 1. Teachers evaluation of workshop techniques

Regarding implementation of strategies in the classroom with target children, planning teachers reported between $74 \%$ and $88 \%$ of the strategies being successfully implemented; however, the strategy that all teachers repeatedly reported difficulty with was involving parents in the intervention process. The second strategy teachers reported difficulty with was assigning space and time for children with ADHD to move around and relax (about 78\% of the cases). During the teacher coaching session, one teacher (T2) argued: "if I let 〈target children> to move around and relax, it is like establishing a trend and I can't deny for other children if they want to....I also don't want the rest of the children to pay attention to a relaxing child while doing their activities".

Teachers evaluated the overall programme effectiveness on a 6-point scale (Figure 2). Participating teachers reported that the behaviour plans they developed for the target children was $77 \%$ effective. The teachers reported that their expectation from the workshops met $83 \%$ of the time. All participating teachers reported that they would 'recommend' or 'very much recommend' the training to other teachers in $85 \%$ of the time. When the teachers were asked how confident they were in managing future behaviours and using the strategies for children with ADHD, all reported that they were 'confident' or 'very confident' ( $93 \%$ of the time).

\section{Overall Programme Effeftivness}

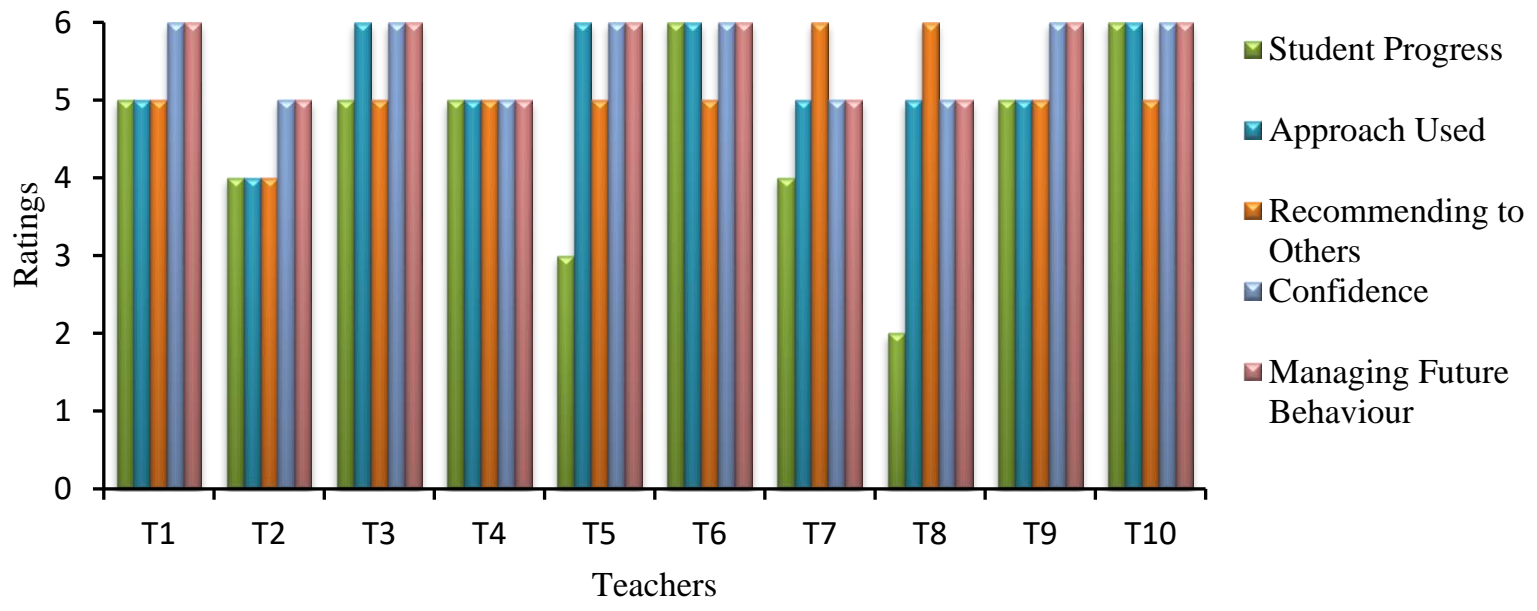

Figure 2. Teachers evaluation of overall programme effectiveness 
Table 3 shows summary of results for the teachers. All participating teachers indicated that they were either confident or very confident to manage future behaviour which was indicated between $83 \%$ and $100 \%$ respectively. Regarding the implementation of the behaviour plans prepared for the target children, six of the seven planning teachers successfully implemented between $80 \%$ and $88 \%$ of the strategies, but one teacher (T8) implemented less (74\%) compared to the rest of planning teachers. This teacher also evaluated the overall programme effectiveness lower than the rest of participating teachers as $75 \%$.

Table 3. Summary of Results for Planning and Team Teachers

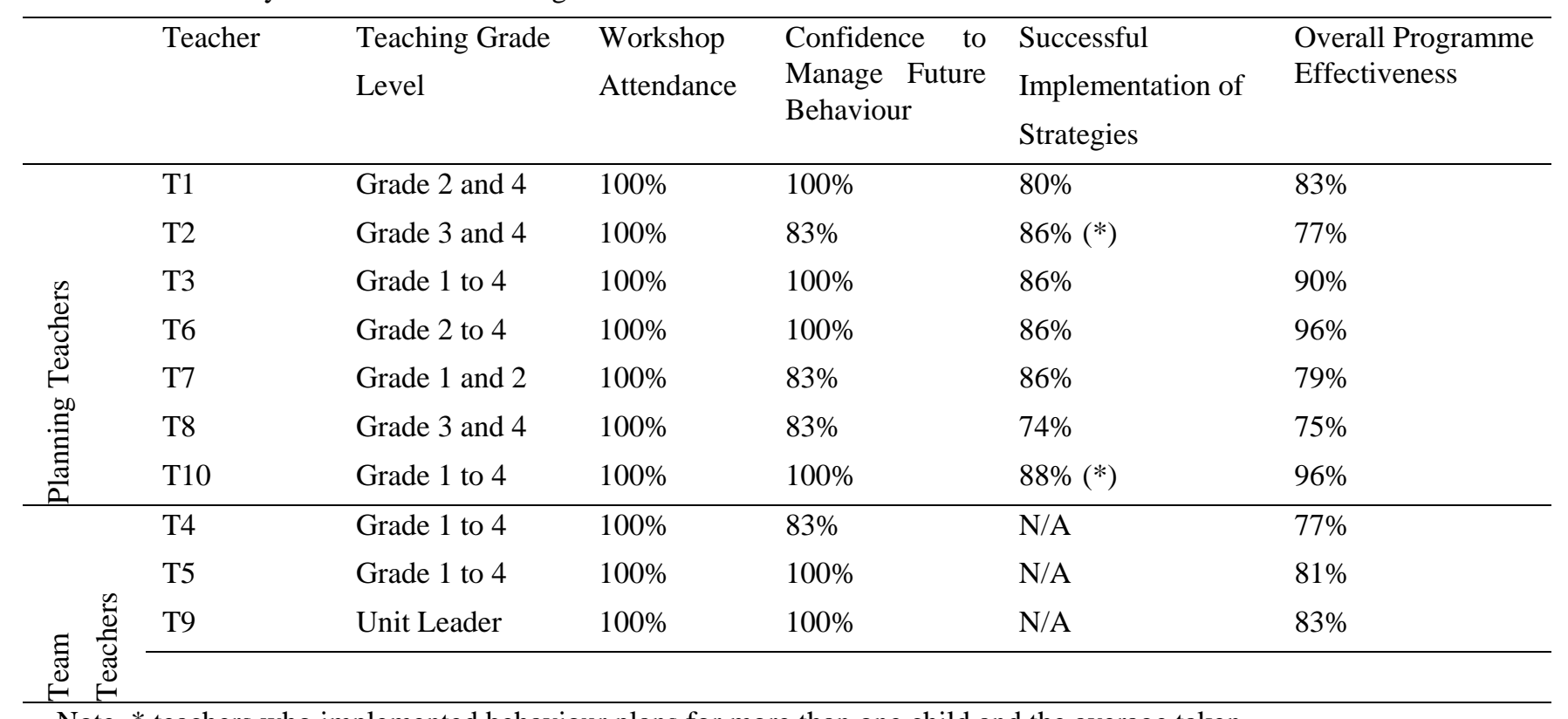

Note. * teachers who implemented behaviour plans for more than one child and the average taken

\section{Discussion}

The present study tailored the standard IYTCM programme for teachers of children with ADHD (IYTCM-ADHD) and evaluated teachers reaction towards the programme in Addis Ababa, Ethiopia. This is the first study to successfully tailor IYTCM for teachers of children with ADHD in the Ethiopian context. The study indicated that an intervention programme which is developed and studied in the western culture and that involves teacher professional development can successfully be tailored and implemented for teachers in Addis Ababa, Ethiopia.

In this study, teachers' acceptance of the IYTCM-ADHD programme and willingness to implement behaviour plans involving different strategies for children with ADHD was examined. The intervention focused on training teachers and helping them to understand children with ADHD symptoms and use spesific strategies to increase the children's on-task behaviour in the classroom. Thus, teachers were able to develop specific behaviour plans focusing on target children's problem behaviours and implemented with close supervision and follow-up.

Results on measures of teacher programme satisfaction showed that participating teachers were happy with the delivery of the programme, its content and the strategies used to help the children in the classroom. Participating teachers reported that they were confident or very confident about using the learned strategies for children with ADHD in the future. Of the 10 teachers, nine reported that they would recommend or strongly recommend the training to other teachers. This shows that the teachers liked the delivery of the IYTCM-ADHD programme and were satisfied with the knowledge and skills they gained from the training. It could also be that they were satisfied with the changes observed in the children's behaviour.

The extent of teacher satisfaction with the IYTCM-ADHD programme in the present study is similar or higher, in many respects, to previous studies (Baker-Henningham et al., 2009; Davenport \& Tansey, 2009; Webster-Stratton et al., 2008). The full attendance and active participation of teachers in the present study indicated that teachers were very much satisfied with the programme and its benefits to the target children with ADHD symptoms. Teachers in the present study evaluated the programme content, video examples, leader's teaching and the group discussion as helpful or very helpful adding up to $100 \%$. This shows that teachers in the present study were more satisfied with the workshop sessions. This could be because all the teachers in the present study reported that they had never received professional development training particularly in classroom management skills since they joined the teaching profession. The study by Serbessa (2006) about the quality of teaching and learning in Ethiopia has also revealed that $87 \%$ of participating teachers in the 
study had never received professional development training since they started teaching. Therefore teachers in the present study may have been exceptionally open to the training as compared to teachers in other countries who receive much more frequent training and up-skilling opportunities.

However, compared to the present study, Webster-Stratton et al. (2008) had higher levels of workshop sessions evaluation from the 153 teachers who received the IYTCM training over a four month period. The authors reported higher teacher satisfaction on the leader's teaching, group discussion and video examples. In the present study, teachers rated the leader's teaching as very helpful as $87 \%$, group discussion as $88 \%$ and video examples as very helpful as $55 \%$. Teachers in the present study also pointed out that the IYTCM standard videos used for the training were not representatives of typical Ethiopian classrooms, and this, therefore, could explain the far lower score for video usefulness.

Teachers in the present study evaluated the workshop techniques implemented particularly the group discussion, role plays and the reference book provided as very important part of the training. The behaviour plan development session of the training also received a positive reaction as important part of the workshop. However, the teachers rated the support received from other teachers/colleges in the classroom the least important. This could be explained by teachers increased confidence in managing classroom behaviours and seeking less support from colleagues.

The results of the present study are consistent with Hutchings et al. (2007) who reported on the programme satisfaction of 23 teachers who received the IYTCM training in a full day session per month for five months. In their study, teachers reported satisfaction with the programme. They reported the usefulness of the programme, improved level of confidence in using the strategies, programme practicality, and improved home-school communications. Teachers in the present study reported the appropriateness of the approach used to change the children's behaviour and improved confidence level in using the strategies in the future, but the teachers scored very much lower in home-school communication.

The present findings are consistent with previous studies of the IYTCM in getting teachers to recommend the programme to colleagues. Of the 10 teachers who participated in the present study, nine reported that they would recommend or very much recommend the training to other teachers. Similarly, Hutchings et al. (2007) also reported that $91 \%$ of the teachers in their study would recommend the course to other teachers. All the teachers in Davenport and Tansey (2009) reported that they would also recommend the training to colleagues.

The present findings are similar to the reports in Davenport and Tansey (2009) where all participating teachers felt confident or very confident about their ability to manage future behaviour problems in children. In the present study, all teachers reported that they were confident or very confident to manage future ADHD related behaviours in their classrooms.

As part of the teacher coaching and supervision, the teacher's level of programme implementation and the difficulties on individually tailored strategies were assessed. One of the difficulties reported regarding the programme implementation was problems with involving parents. Almost all teachers in the present study reported that they struggled to involve parents in the intervention process, particularly in using daily behaviour report cards and involving parents in home praise/reward system. This may have an impact on the result reducing the potential level of effectiveness of the intervention. Similar concern has been raised in Davenport and Tansey (2009) study in which teachers who received the IYTCM training expressed their wish to give greater attention to working with parents. Similarly, results in Carlson et al. (2011) did not indicate significant changes in teacher's use of strategies to enhance home-school communication. In reports of teacher programme satisfaction by Hutchings et al. (2007), home-school collaboration and working with parents was one of the strategies that received the lowest ratings by teachers compared to the other strategies of the programme evaluated.

It is not surprising to find out that teachers in the Ethiopian context were not successful in improving their relationship with parents and involving parents in the intervention process. In the Ethiopian school system, the direct involvement of parents in the education of their child/children is negligible (Kahsay, 2006). Therefore, in order to improve the teacher-parent relationship, a different strategy might be needed in the Ethiopian context other than those prescribed in the IYTCM manual.

Teacher attitude towards planning time and space for children with ADHD to help them move around and relax between activities seems unfavourable. Similarly, the application of emotional coaching seems difficult for a few teachers. It could be that the Ethiopian education system generally focuses on academic coaching rather than nurturing the children's emotions.

\section{Conclusion}

The present study indicated that the IYTCM package could be successfully tailored for children with ADHD symptoms in the Ethiopian context and participating teachers fully involved in the intervention programme. The teachers indicated 
that they were satisfied with the delivery of the programme and its content. The application of the tailored IYTCM -ADHD programme could be one of the most important factors in determining the positive results in this study. The IYTCM programme is originally developed for children with conduct disorder; hence specific steps have been followed tailoring the programme for children with ADHD.

The other explanation for the improved result could be the shorter timeframe implemented to deliver the programme. The standard IYTCM programme has been delivered ranging from 2-hour session per week to 6-hour session (full-day) workshop format with sessions held once a month and spread out over five to 12 months. The tailored IYTCM-ADHD programme was successfully delivered once a week over six weeks. The weekly full-day (6-hour) workshop helped to incorporate the theoretical explanations of the IYTCM-ADHD programme with the practical skills and role plays for each strategy without creating a gap. Moreover, the week-long practice time was long enough to meet each teacher and provide immediate feedback on the implementation of specific strategies.

Another reason for the better result could be teacher's limited access to professional development particularly in classroom management skills training. None of the participating teachers had received training on classroom management skills before joining this programme. They may, therefore, have been exceptionally open to the training, as compared to teachers in other countries who receive much more frequent training and skill development opportunities.

The findings of the present study suggested that primary school teachers in Ethiopia need specific training on classroom management techniques to realize inclusion of children with ADHD. To achieve this, the IYTCM-ADHD training programme could be integrated with teacher education programmes or offered as in-service training for groups of teachers at a time.

The next steps that are important to consider while developing research in evaluating the IYTCM-ADHD programme for teachers of children with ADHD could be identifying which strategies are most effective. The IYTCM-ADHD programme is a package that generally aims to enhance teacher's skills and in turn enhances the children's competence and social skills. Never-the-less, it is important to identify the most effective strategies that affect individual children's behaviour.

Although encouraging findings of the IYTCM-ADHD have been indicated in the present study, some limitations should be noted. Primarily, a posttest-only design was implemented to collect the data. Because of time constraint, the teachers' classroom management strategies before the intervention particularly for children with ADHD were not measured as the teacher training had to start as soon as possible before the end of the academic year. In addition to the time limitation, the teachers' pre-intervention classroom management was not measured because of the following reasons: (a) it is difficult to recruit teachers or schools to participate in the study, especially in the Ethiopian context, as this might cause anxiety around teachers being observed in the classroom; (b) it is difficult to train observers to code teacher behaviour concurrently with the children's behaviour; (c) it is more difficult for the researcher (group leader) to be accepted both as a support person and an evaluator; and (d) it may also interfere with the teacher's practice and willingness to try strategies freely in the classroom; without thinking that they must do it to 'perfection'.

The second limitation important to mention here is that the children who participated in the present study had not been clinically diagnosed. The children were selected based on teacher and parent reports of behaviour based on the DSM-IV-TR criteria, however, the present findings could be different if the children were clinically diagnosed considering the revised criteria of the DSM-V. In turn, these could affect the teachers' level of implementation of the strategies and the perceived effectiveness of the programme.

\section{Acknowledgments}

I would like to take this opportunity to thank my academic supervisors Kathleen Liberty, Associate Professor and Early Intervention Programme Coordinator, School of Health Sciences, University of Canterbury, and Michael Tarren-Sweeney, Professor in Child and Family Psychology, School of Health Sciences, University of Canterbury, for their immense contribution during the course of this research.

This study was partly supported by UC Doctoral Scholarship received from the College of Education, University of Canterbury, New Zealand.

\section{References}

American Psychiatric Association. (2000). Diagnostic and statistical manual of mental disorders (4th ed.). Washington DC: American Psychiatric Association. https://doi.org/10.1176/appi.books.9780890425596

American Psychiatric Association. (2013). Diagnostic and statistical manual of mental disorders: DSM-5. Washington, D.C: American Psychiatric Association.

Arnold, L. E., Hodgkins, P., Kahle, J., Madhoo, M., \& Kewley, G. (2015). Long-Term Outcomes of ADHD: Academic 
Achievement and Performance. Journal of Attention Disorders, (1-13). Sage Publications. https://doi.org/10.1177/1087054714566076

Bakare, M. (2012). Attention deficit hyperactivity symptoms and disorder (ADHD) among African children: A review of epidemiology and co-morbidities. African Journal of Psychiatry, 15(5), 358-361.

https://doi.org/10.4314/ajpsy.v15i5.45

Baker-Henningham, H., Scott, S., Jones, K., \& Walker, S. (2012). Reducing child conduct problems and promoting social skills in a middle-income country: Cluster randomised controlled trial. The British Journal of Psychiatry, 201(2), 101-108. https://doi.org/10.1192/bjp.bp.111.096834

Baker-Henningham, H., Walker, S., Powell, C., \& Gardner, J. M. (2009). A pilot study of the Incredible Years teacher training programme and a curriculum unit on social and emotional skills in community pre-schools in Jamaica. Child: Care, Health and Development, 35(5), 624-631. https://doi.org/10.1111/j.1365-2214.2009.00964.x

Barkley, R. A. (2006). Attention Deficit Hyperactivity Disorder: A handbook for diagnosis and treatment (3rd ed.). New York: Guilford Press.

Barkley, R. A. (2015). Attention Deficit Hyperactivity Disorder: A Handbook for Diagnosis and Treatment (4 ${ }^{\text {th }}$ ed.). New York: The Guilford Press.

Baweja, R., Mattison, R. E., \& Waxmonsky, J. G. (2015). Impact of Attention-Deficit Hyperactivity Disorder on School Performance: What are the Effects of Medication? Paediatric Drugs, 17(6), 459-477.

https://doi.org/10.1007/s40272-015-0144-2

BBC News. Ethiopia is one of the world's fastest growing economies [Video file]. (2011, November 15). Retrieved from http://www.bbc.com/news/av/world-africa-15739706/ethiopia

Carlson, J. S., Tiret, H. B., Bender, S. L., \& Benson, L. (2011). The influence of group training in the Incredible Years Teacher Classroom Management Program on preschool teachers' classroom management strategies. Journal of Applied School Psychology, 27(2), 134-154. https://doi.org/10.1080/15377903.2011.565277

Carroll, A., Houghton, S., Taylor, M., Hemingway, F., List-Kerz, M., Cordin, R., \& Douglas, G. (2006). Responding to interpersonal and physically provoking situations in classrooms: Emotional intensity in children with attention deficit hyperactivity disorder. International Journal of Disability, Development and Education, 53(2), 209-227. https://doi.org/10.1080/10349120600716174

Clarke, A. T, Marshall, S. A., Mautone, J. A., Soffer, S. L., Jones, H. A., Costigan, T. E., ... Power, T. J. (2015). Parent attendance and homework adherence predict response to a family-school intervention for children with ADHD. Journal of Clinical Child \& Adolescent Psychology, 44(1), 58-67. https://doi.org/10.1080/15374416.2013.794697

Corkum, P., McGonnell, M., \& Schachar, R. (2010). Factors affecting academic achievement in children with ADHD. Journal of Applied Research on Learning, 3, 1-14.

Daly, P. M., \& Ranalli, P. (2003). Using countoons to teach self-monitoring skills. Teaching Exceptional Children, 35(5), 30-35. https://doi.org/10.1177/004005990303500504

Davenport, J., \& Tansey, A. (2009). Outcomes of an Incredible Years Classroom Management Programme with Teachers from Multiple Schools (Research Report). Retrieved from http://www.incredibleyears.com/wp-content/uploads/outcomes-incredible-years-classroom-dublin_09.pdf

Dekkers, T. J., Agelink van Rentergem, J. A., Koole, A., van den Wildenberg, W., Popma, A., Bexkens, A., ... Huizenga, H. M. (2017). Time-on-task effects in children with and without ADHD: depletion of executive resources or depletion of motivation?. European child \& adolescent psychiatry, 26(12), 1471-1481. https://doi.org/10.1007/s00787-017-1006-y

Do2learn. (2010). Volcano Scale-My School Triggers. Retrieved March 14, 2012, from https://do2learn.com/activities/SocialSkills/Stress/VocanoScale-MySchoolTriggers.pdf

DuPaul, G. J., Eckert, T. L., \& Vilardo, B. (2012). The effects of school-based interventions for attention deficit hyperactivity disorder: A meta-analysis 1996-2010. School Psychology Review, 41(4), 387-412.

Ellis, A. M. (2013). Teacher Stress and Attention Deficit/Hyperactivity Disorder (Honors theses, University of Southern Mississippe). Retrieved from http://aquila.usm.edu/honors_theses

Flick, G. L. (2010). Managing ADHD in the K-8 classroom: A teacher's guide. Thousand Oaks, California: Corwin.

Gray, A. (2018, May 04). Ethiopia is Africa's fastest-growing economy. Retrieved from the World Economic Forum website: https://www.weforum.org/agenda/2018/05/ethiopia-africa-fastest-growing-economy/ 
Hutchings, J., Daley, D., Jones, K., Martin, P., Bywater, T., \& Gwyn, R. (2007). Early results from developing and researching the Webster-Stratton Incredible Years Teacher Classroom Management Training Programme in North West Wales. Journal of Children's Services, 2(3), 15-26. https://doi.org/10.1108/17466660200700023

Hutchings, J., Martin-Forbes, P., Daley, D., \& Williams, M. E. (2013). A randomized controlled trial of the impact of a teacher classroom management program on the classroom behavior of children with and without behavior problems. Journal of School Psychology, 51(5), 571-585. https://doi.org/10.1016/j.jsp.2013.08.001

Imeraj, L., Antrop, I., Sonuga-Barke, E., Deboutte, D., Deschepper, E., Bal, S., \& Roeyers, H. (2013). The impact of instructional context on classroom on-task behavior: A matched comparison of children with ADHD and non-ADHD classmates. Journal of School Psychology, 51(4), 487-498. https://doi.org/10.1016/j.jsp.2013.05.004

Jitendra, A. K., DuPaul, G. J., Someki, F., \& Tresco, K. E. (2008). Enhancing academic achievement for children with attention-deficit hyperactivity disorder: Evidence from school-based intervention research. Developmental Disabilities Research Reviews, 14(4), 325-330. https://doi.org/10.1002/ddrr.39

Kahsay, A. N. (2006). Parental involvement in the education of their children: A case study of one government primary school in Addis Ababa, Ethiopia. (Unpublished master's thesis), University of Oslo, Norway. Retrieved from http://urn.nb.no/URN:NBN:no-12829 (12829)

Kocsev, M., Hansen, N., Hollow, D., \& Pischetola, M. (2009). Innovative learning in Ethiopia

Luman, M., Oosterlaan, J., \& Sergeant, J. A. (2005). The impact of reinforcement contingencies on AD/HD: A review and theoretical appraisal. Clinical Psychology Review, 25(2), 183-213. https://doi.org/10.1016/j.cpr.2004.11.001

McIntyre, L. L. (2008). Adapting Webster-Stratton's Incredible Years Parent Training for children with developmental delay: Findings from a treatment group only study. Journal of Intellectual Disability Research, 52(12), 1176-1192. https://doi.org/10.1111/j.1365-2788.2008.01108.x

Messaria, T. A. (2013). Attention Deficit Hyperactivity Disorder among children in elementary schools of Addis Ababa: Prevalence, correlates and comorbidity (Doctoral Dissertation). Addis Ababa University.

National Sleep Foundation. (n.d.). Sleep for Children. Retrieved from https://sleepfoundation.org/

Perold, H., Louw, C., \& Kleynhans, S. (2010). Primary school teachers' knowledge and misperceptions of Attention Deficit Hyperactivity Disorder (ADHD). South African Journal of Education, 30(3). https://doi.org/10.15700/saje.v30n3a364

Portela, M. O., \& Pells, K. (2015). Corporal Punishment in Schools: Longitiudinal Evidence from Ethiopia, India, Peru and Viet Nam.(Discussion Paper), UNICEF Office of Research-Innocenti, Florence.

Shaughnessy, M. F., \& Waggoner, C. R. (2015). The Educational Implications of ADHD: Teachers and Principals Thoughts Concerning Students with ADHD. Creative Education, 6, 215-223.

https://doi.org/10.4236/ce.2015.62020

Sung, V., Hiscock, H., Sciberras, E., \& Efron, D. (2008). Sleep problems in children with Attention-Deficit/Hyperactivity Disorder: Prevalence and the effect on the child and family. Archives of Pediatrics \& Adolescent Medicine, 162(4), 336. https://doi.org/10.1001/archpedi.162.4.336

Vaughn, S., \& Klingner, J. (1999). Teaching reading comprehension through collaborative strategic reading. Intervention in School and Clinic, 34(5), 284-292. https://doi.org/10.1177/105345129903400505

Vile Junod, R. E., DuPaul, G. J., Jitendra, A. K., Volpe, R. J., \& Cleary, K. S. (2006). Classroom observations of students with and without ADHD: Differences across types of engagement. Journal of School Psychology, 44(2), 87-104. https://doi.org/10.1016/j.jsp.2005.12.004

Visser, S. N., Danielson, M. L., Bitsko, R. H., Holbrook, J. R., Kogan, M. D., Ghandour, R. M., ... Blumberg, S. J. (2014). Trends in the parent-report of health care provider-diagnosed and medicated attention-deficit/hyperactivity disorder: United States, 2003-2011. Journal of the American Academy of Child \& Adolescent Psychiatry, 53(1), 34-46. https://doi.org/10.1016/j.jaac.2013.09.001

Walker, H. M., Colvin, G., \& Ramsey, E. (1995). Antisocial Behavior in School: Strategies and best practices USA: Brooks/Cole Publishing Company.

Webster-Stratton, C. (1999). How to promote children's social and emotional competence. London: Sage

Webster-Stratton, C. (2008). The Incredible Years: Teacher training program leader's workshop handouts. Author.

Webster-Stratton, C., \& Reid, M. J. (2010). Adapting the Incredible Years: An evidence-based parenting programme for families involved in the child welfare system. Journal of Children's Services, 5(1), 25-42. 
https://doi.org/10.5042/jcs.2010.0115

Webster-Stratton, C., Reid, J. M., \& Stoolmiller, M. (2008). Preventing conduct problems and improving school readiness: Evaluation of the Incredible Years teacher and child training programs in high-risk schools. Journal of Child Psychology and Psychiatry,

Zhou, R., Xia, Q., Shen, H., Yang, X., Zhang, Y., \& Xu, J. (2015). Diagnosis of children's attention deficit hyperactivity disorder (ADHD) and its association with cytomegalovirus infection with ADHD: a historical review. International journal of clinical and experimental medicine, 8(8), 13969-13975.

\section{Copyrights}

Copyright for this article is retained by the author(s), with first publication rights granted to the journal.

This is an open-access article distributed under the terms and conditions of the Creative Commons Attribution license which permits unrestricted use, distribution, and reproduction in any medium, provided the original work is properly cited. 